\title{
Enablers and barriers for enteral feeding with mother's own milk in preterm very low birth weight infants in a tertiary care neonatal intensive care unit
}

\author{
Dattatray Kulkarni ${ }^{\oplus}$, Srinivas Murki ${ }^{\oplus}$, Dinesh Pawale ${ }^{\oplus}$, Soumya Jena ${ }^{\oplus}$, \\ Deepak Sharma ${ }^{\oplus}$, Venkateshwarlu Vardhelli॰ ${ }^{\oplus}$ Venkat Kallem ${ }^{\oplus}$, Tanveer Bashir ${ }^{\oplus}$, \\ Vidhyadhara Naik ${ }^{\bullet}$, Sai Kiran ${ }^{\circ}$ \\ Department of Neonatology, Fernandez Hospital, Hyderguda, Hyderabad, Telangana, India.
}

\begin{abstract}
Background. The management of lactation in preterm mothers is a real challenge for Neonatal Intensive Care Unit (NICU) care, providers. The study aimed to evaluate the enablers and barriers for enteral feeding with mothers' own milk (MOM) in preterm very low birth weight (VLBW) infants in a tertiary care neonatal unit.

Methods. This prospective observational study took place at a tertiary level NICU of a high-risk obstetric unit in a private hospital. All VLBW infants and mothers were incorporated into the study. Data on enablers and barriers were gathered from mother-baby dyads at the time of birth, at the end of the 7th day, and then weekly till the discharge of the baby from the unit.

Results. We studied 87 mother-baby dyads. Mean (SD) maternal age, gestation age and birth weight were 29.3 (4.7) years, 30.8 (2.0) weeks, and 1196 (196) grams respectively. We categorized our data into 2 groups based on outcome estimates done during the entire hospital stay or pre-discharge (48 hours before the discharge). On comparison of perinatal and post-natal factors, the enablers were maternal dwelling from the rural locality, number of milk expression son day 1 after the birth, number of night expressions in the first week postnatally, and MOM volume till day 3, day 7, and 2 weeks postnatally. The enablers of MOM in the pre-discharge group were the number of expressions in the first 3 days, the number of night expressions in week 1, mother's visit, and the number of maternal visits on day 1 to NICU and MOM volume expressed from day 1 until the second week after birth. The main barriers for MOM (48 hours pre-discharge) were extremely low birth weight (ELBW) and intrauterine growth-restricted infants (IUGR).

Conclusions. ELBW infants and IUGR infants are susceptible to low MOM feeding. The total of milk expressions in the first 3 days, number of night expressions in the first week, maternal visits on day 1 and the average MOM amount in the first 2 weeks are enablers for MOM feeding.
\end{abstract}

Key words: mother own milk, ELBW, IUGR, milk expression.

There are about 15 million preterm births per year worldwide. Preterm childbirth incidence has increased in the last 20 years in 62 of 65 countries with available data trends. More than 1 million children succumb to preterm birth-

Dattatray Vasantrao Kulkarni devdk.kulkarni@gmail.com

Received 24th May 2020, revised 7th August 2020, 4th November 2020, 6th January 2021,

accepted 14th January 2021. related complexities yearly. Preterm childbirths are the leading cause of neonatal death and the second most common cause of mortality after pneumonia for less than 5 years of age mortality rate. ${ }^{1}$ Breastfeeding and donor human milk benefits for giving ideal nutrition and immune protection are well known. ${ }^{2}$ It reduces the risk of respiratory infection, necrotizing enterocolitis, gastrointestinal infection, and improves neurodevelopmental outcomes. Mothers' own milk (MOM) incorporates hormones, 
growth factors, immunological factors, so it is an exhaustive nutrient source for preterm newborns. Human milk is nutritionally rich and immunologically superior so very crucial for preterm survival and has immense value in a resource-limited environment. ${ }^{2,3} \mathrm{MOM}$ provides optimum nutrition for both term and preterm infants. The use of human milk for preterm infants is not only nutritional but it sustains host defense, helps in the maturation of the gastrointestinal system and sensory neural development. ${ }^{3,4}$ Mothers of preterm infants are at greater risk of low initiation of breastfeeding in contrast to term infants. The breastfeeding of term infants has been thoroughly studied and data on facilitators and obstacles are available, but preterm breastfeeding appears more complicated because of its rate and the fact that factors increasing and decreasing preterm breastfeeding have not been studied effectively when compared to term infants. ${ }^{5}$ Breastfeeding in the term, as well as preterm, is affected by various factors like maternal, infant, social, and cultural factors. Maternal factors are sociodemographic factors, physiological aspects, earlier breastfeeding experience and support from family members whereas infant factors are birth gestation age, neonatal morbidity, and social factors are perspective of the society, culture, maternity benefits, and health care factors are staff attitude, staffing figure, advice and arrangement of the neonatal unit, which are all of importance. ${ }^{6}$ However, very few studies are available on human milk and the factors affecting it. Recognizing the low breastfeeding rate in preterm mothers will help us understand the complicated nature of preterm breastfeeding and various factors promoting and prohibiting its uses and its outcome on preterm infants. ${ }^{5}$

The objective of our study was to assess enablers and barriers of favorable MOM use among preterm very low birth weight infants.

\section{Material and Methods}

A prospective observational study was carried on the preterm infants admitted to the Neonatal
Intensive Care Unit (NICU) during the study period of 6 months from August 2017 to January 2018. The infant was included if they were born $\leq 34$ weeks of gestation age and weighing $<1500$ grams at birth. The infant was excluded if they had any of the following:

- Mother admitted to ICU due to critical illness

- HIV (human immunodeficiency virus) positive mother who is reluctant to give MOM

- Infants having major congenital anomalies

- Infants depending upon surgical intervention where we must manage them nil per oral.

- Infants who died or were discharged or transferred to another hospital

The study was approved by the ethical committee of the Fernandez Hospital (reference number 24_2017). All the appropriate VLBW infants and their mothers were enrolled in the study after obtaining their informed consent.

\section{Sample size:}

A sample was obtained from the baseline phase of a QI (quality initiative) study run at Fernandez Hospital. No prior sample was estimated.

\section{Study technique:}

The data gathered consisted of the perinatal variables, milk expressions, daily proportion of enteral feeds (MOM and donor human milk (DHM)), management of breast pump and type of breast pump utilized, hours of skin to skin interaction, non-nutritive sucking, and care hours (time devoted to infant care activities) by mothers. The numbers of maternal visits, kangaroo mother care hours were also compiled prospectively. The data on enablers and barriers were gathered from the mother and family members at the time of birth, at the end of the 7th day, and weekly until the discharge of infants from the neonatal unit. We assessed 87 VLBW infants to identify the enablers and 
barriers for human milk uses. The enablers and barriers assessed in this study are summarized in Table I. We recorded the volume of the milkfed to the infants daily in the first week after birth than on the weekly basis for the total NICU stay and at the time of discharge (milk intake by the infants 48 hours before discharge from NICU) prospectively for estimation of following outcomes:

- Amount of MOM intake

- Amount of DHM

- Amount of total milk intake famount of MOM and amount of DHM) and formula milk (FM)\}

Every day from the time enteral feeding started, the amount of milk fed to the infant was prospectively recorded. For the recognition of enablers or barriers of use of MOM, very low birth weight infants with MOM intake of more than $60 \%$ of total enteral intake were regarded as infants with MOM success. We divided our infants into 2 groups as the MOM success group and the MOM failure group for assessing enablers and barriers for MOM . We counted the proportion of infants with MOM success for both during the NICU stay and at the time of discharge (48 hours before discharge from the NICU).

\section{Outcome Measures:}

Successful MOM uses for each group at the time of discharge and during the hospital stay was represented as an enteral intake of more than $60 \%$ of MOM out of the total volume of milk intake by infants.

Table I. Enablers and barriers evaluated in the study.

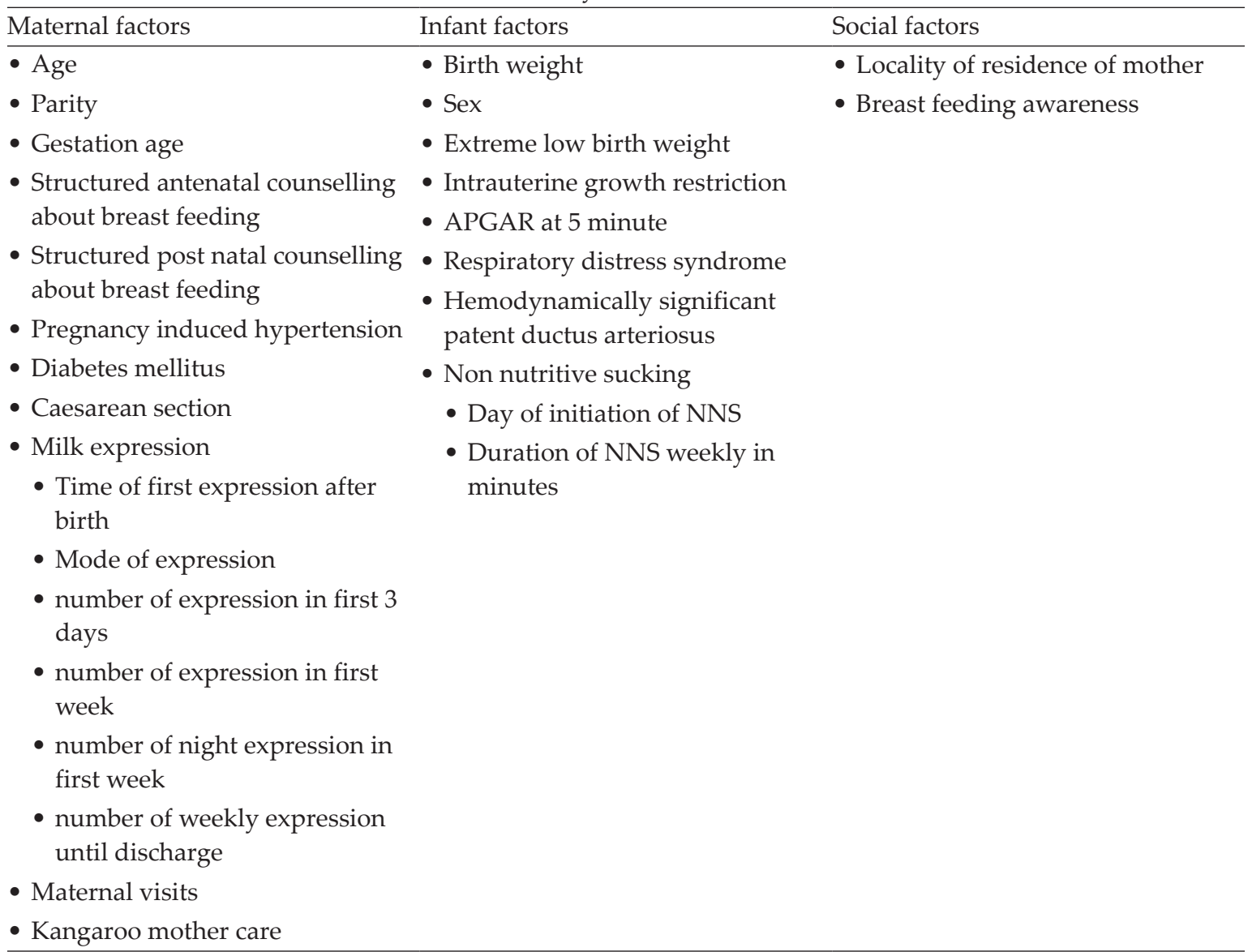

NNS: Non nutritive sucking 


\section{Statistical analysis:}

All the data during the study which were registered were filled in into the Microsoft XL sheet. The data was solved statistically by using statistical software SPSS version 20. All data were revealed as mean (standard deviation) and proportions where ever as relevant. The Chisquare test and student $\mathrm{t}$-test were administered for all qualitative data and quantitative data respectively. A "p-value" of $<0.05$ was taken as significant.

\section{Result}

During the study span, a total of 93 motherinfant dyads were enrolled and 6 dyads were omitted of which five infants had died, and one was discharged against medical advice. The study outcomes were evaluated in the remaining 87-eligible mother-infant dyads that were discharged from the hospital. Of these mother-infant dyads, 32 (36.7\%) had successful MOM use, pre-discharge (48 hours before discharge) and 43 mother-infant dyads (49.4\%) had successful MOM use during the total hospital stay.

In the MOM (48 hours prior discharge) group and FM or DHM group, mean maternal age, mean gestation age, education level, and mother having medical disorder (pregnancy-induced hypertension and gestational diabetes mellitus), were identical. In the MOM (48 hours before discharge) group, $50 \%$ were primigravida, which were statistically not significant. The proportion of women with c-section was greater in the formula or DHM group (87 vs $72 \%$ ) but not statistically significant. The proportion of mothers residing from the rural locality was greater in infants with MOM success. None of the mothers in either group had structured antenatal counseling about breastfeeding and thus the breastfeeding awareness in both groups was at 19\% and 18\% in the MOM group and FM or DHM group respectively. Also, none had first-day and firstweek postnatal counseling on breastfeeding practice. The proportion of infants with birth weight less than 1000 grams and the incidence of intrauterine growth restriction (IUGR) were significantly larger in the FM or DHM group. The incidence of respiratory distress syndrome (RDS), hemodynamically significant patent ductus arteriosus (HSPDA), and requirement of invasive ventilation or noninvasive ventilation (continuous positive airway pressure (CPAP) heated high flow nasal cannula (HHFNC)) in MOM (48 hours prior discharge) and FM or DHM group were comparable. APGAR score at five minutes in both groups was identical, mean of 8/10 (Table II).

The evaluation of the barriers and enablers of MOM (48 hours before discharge) use and the enablers of MOM (48hours prior discharge) are given below (Table III)

- Total night feeding (expression) in the first week

- Total number of milk expression until the first 3 days after birth

- Maternal visit to the NICU on the first day

- Total number of maternal visits on the first day to the NICU

- The average volume of MOM on the first day, second day to the third day, from day four until day seven, and in the second week after birth.

The major barriers for MOM (48 hours before discharge)

- Extremely low birth weight (ELBW) (Birth weight less than 1000 grams) infants

- IUGR infants

All other factors detailed below neither increased the MOM (pre-discharge usage) or lessened its use

- Total number of milk expressions on the first day

- Time of first milk expression after the birth

- Total number of milk expressions on the first day, until day seven and during a hospital stay 
Table II. Comparison of Pre-discharge (Before 48 hrs) MOM success vs. MOM Failure Group for baseline variable.

\begin{tabular}{|c|c|c|c|}
\hline Baseline variable & $\begin{array}{l}\text { MOM Success } \\
(\mathrm{n}=32)\end{array}$ & $\begin{array}{l}\text { MOM Failure } \\
(\mathrm{n}=55)\end{array}$ & $P$ value \\
\hline Primigravida mother & $16(50 \%)$ & $29(53 \%)$ & 0.78 \\
\hline Cesarean section & $23(72 \%)$ & $48(87 \%)$ & 0.07 \\
\hline Maternal age (years) & 29.09(SD \pm 4.4$)$ & $29.45(\mathrm{SD} \pm 4.9)$ & 0.73 \\
\hline Maternal PIH & $18(56 \%)$ & $24(44 \%)$ & 0.25 \\
\hline Maternal diabetes & $4(12.5 \%)$ & $10(18 \%)$ & 0.48 \\
\hline \multicolumn{4}{|l|}{ Education } \\
\hline Matriculation & $2(6 \%)$ & $2(4 \%)$ & 0.57 \\
\hline Intermediate & $11(34 \%)$ & $13(24)$ & 0.27 \\
\hline Graduate & $11(34 \%)$ & $32(58 \%)$ & 0.03 \\
\hline Post graduate & $8(25 \%)$ & $8(15 \%)$ & 0.22 \\
\hline \multicolumn{4}{|l|}{ Residence } \\
\hline Rural & $4(13 \%)$ & $1(1.8 \%)$ & 0.045 \\
\hline Semi urban & $3(9 \%)$ & $13(24 \%)$ & 0.29 \\
\hline Urban & $25(78 \%)$ & $41(74.2 \%)$ & 0.84 \\
\hline Breastfeeding awareness & $6(19 \%)$ & $10(18 \%)$ & 0.94 \\
\hline Gestation (week) & $30.6(\mathrm{SD} \pm 1.6)$ & $30.8(\mathrm{SD} \pm 2.2)$ & 0.64 \\
\hline Birth weight (gram) & $1244(\mathrm{SD} \pm 165)$ & $1168(\mathrm{SD} \pm 208)$ & 0.08 \\
\hline Male sex & $22(69 \%)$ & $30(55 \%)$ & 0.19 \\
\hline ELBW & $2(6.3 \%)$ & $14(25.5 \%)$ & 0.02 \\
\hline IUGR & $6(19 \%)$ & $24(44 \%)$ & 0.02 \\
\hline APGAR 5min & 8 (IQR 8-8) & 8 (IQR 8-8) & 1.00 \\
\hline RDS & $30(94 \%)$ & $47(85 \%)$ & 0.24 \\
\hline HSPDA & $12(38 \%)$ & $27(49 \%)$ & 0.29 \\
\hline Ventilation & $2(6.3 \%)$ & 7 (12.7\%) & 0.34 \\
\hline HFNC/CPAP & $19(59 \%)$ & $38(69 \%)$ & 0.35 \\
\hline
\end{tabular}

MOM: mother own milk, PIH: pregnancy induced hypertension, ELBW: extremely low birth weight (birth weight $<1000$ grams), IUGR: intra-uterine growth restriction, RDS: respiratory distress syndrome, HSPDA: hemodynamically significant patent ductus arteriosus CPAP: continuous positive pressure support HFNC: high flow nasal canula, SD: standard deviation, IQR: interquartile range

- Mode of the milk expression by electronic pump or by manual hand

- Maternal visit from day two to $3^{\text {rd }}$ day, $4^{\text {th }}$ to $7^{\text {th }}$ day and until the end of the first week

- Mean minutes of visits to the NICU on the first day, second post-natal day to third post-natal day and day four to $7^{\text {th }}$ day

- Time of the first contact of mothers with their infants

- Mean of the time of the first non nutritive sucking (NNS) and mean duration of NNS
- Mean of the time of first skin to skin contact and mean duration of skin to skin contact

On testing, of perinatal and post-natal factors during the total hospital stay for infants with MOM success with the control mother-infant dyad; baseline variables were similar between the 2 groups. The ELBW infants and IUGR infants were similar throughout the entire hospital stay which was conflicting with predischarge state. Maternal visits were also not significantly different between the groups. Even 
Table III. Comparison of Pre-discharge (Before 48 hrs) MOM success vs. MOM Failure Group for enables and barrier.

\begin{tabular}{|c|c|c|c|}
\hline Factors & $\begin{array}{l}\text { MOM Success } \\
(\mathrm{n}=32)\end{array}$ & $\begin{array}{l}\text { MOM Failure } \\
(\mathrm{n}=55)\end{array}$ & $P$ value \\
\hline Antenatal counseling & 0 & 0 & 0 \\
\hline Breastfeeding awareness & $6(19 \%)$ & $10(18 \%)$ & 0.94 \\
\hline Day 1 counseling & 0 & 0 & 0 \\
\hline $\begin{array}{l}\text { Proportion of the mothers who Expressed the milk on } \\
\text { Day1 after birth }\end{array}$ & $25(78 \%)$ & $39(71 \%)$ & 0.615 \\
\hline Time of first expression after birth (hours) & $12(\mathrm{IQR} 7-24)$ & 18 (IQR 14-27) & 0.14 \\
\hline Median number of expressions Day1 after birth & 2 (IQR 0-2) & 1 (IQR 0-1) & 0.057 \\
\hline Median number of expressions in first 3 days after birth & 6 (IQR 5-8) & 5 (IQR 4-6) & 0.049 \\
\hline Median number of expressions in first week after birth & 17 (IQR 14-20) & 16 (IQR 13-18) & 0.114 \\
\hline Median number of night expressions in first week & 5 (IQR 4-6) & $4(\mathrm{IQR} 2-4)$ & 0.001 \\
\hline Median number of total Expressions in NICU stay & 78 (IQR 61-103) & 52 (IQR 30-102) & 0.10 \\
\hline \multicolumn{4}{|l|}{ Mode of expressions } \\
\hline Only pump & $24(75 \%)$ & $32(58 \%)$ & 0.11 \\
\hline Both (manual and pump) & $8(25 \%)$ & $23(42 \%)$ & \\
\hline Mother having Any Visit on Day 1 & $9(28 \%)$ & $3(5.5 \%)$ & 0.003 \\
\hline Maternal visit on day 1 (median numbers) & 0 (IQR 0-1) & 0 (IQR 0-0) & 0.008 \\
\hline Maternal visit on day 2-3 (median numbers) & 2 (IQR 1-4) & 2 (IQR 1-3) & 0.776 \\
\hline Maternal visit on day 4-7(median numbers) & 3 (IQR 1-5) & 3 (IQR 1-4) & 0.308 \\
\hline Maternal visits in the first week (median numbers) & 16 (IQR 7-29) & 13 (IQR 7-30) & 0.36 \\
\hline Minutes of visit on day 1 (median) & 0 (IOR 0-5) & 0 (IQR 0-0) & 0.25 \\
\hline Minutes of visit on day 2- 3 (median) & 15 (IQR 10-30) & 10 (IQR 4-20) & 0.92 \\
\hline Minutes of visit on day 4- 7(median) & 40 (IQR 20-150) & 32 (IQR 13-121) & 0.36 \\
\hline Time of first contact (in hrs) after birth with infant & 30 (IQR 23-50) & 38 (IQR 29-72) & 0.88 \\
\hline $\begin{array}{l}\text { Time of first Non-Nutritive sucking done for infant (day } \\
\text { of life after birth) }\end{array}$ & 7 (IQR 5-9) & 8 (IQR 7-13) & 0.525 \\
\hline $\begin{array}{l}\text { Non -Nutritive sucking (in Min) done for infant in the } \\
\text { first week }\end{array}$ & 5 (IQR 0-10) & 0 (IQR 0-5) & 0.234 \\
\hline Day of initiation of Skin to skin care for infant after birth & 7 (IOR 5-10) & 8 (IQR 6-10) & 0.542 \\
\hline Median duration of Skin to skin (hrs) done in NICU stay & 21 (IQR 11-32) & 26 (IQR 5.7-43.4) & 0.796 \\
\hline Median duration of KMC in first week & 0 (IQR 0-3) & 0 (IQR 0-2) & 0.92 \\
\hline Median MOM volume on day 1 & 1 (IQR 0-4) & 0 (IQR 0-1) & 0.014 \\
\hline Median MOM volume on day 2-3 & 20 (IQR 8-44) & 3.5 (IQR 0-18) & 0.001 \\
\hline Median MOM volume on day 4-7 & 227 (IQR 95-512) & 76.5 (IQR 17.7-246) & 0.011 \\
\hline Median MOM volume in $2^{\text {nd }}$ week & 1263 (IQR 640-1588) & 222 (IQR 31-606) & $<0.000$ \\
\hline
\end{tabular}

MOM: mother own milk, NICU: neonatal intensive care unit, KMC: kangaroo mother care, IQR: interquartile range

though the number of mothers was less from the rural locality in the total number of studied mother-infant dyads it still preserved its effect. The numbers of expressions on day 1 , number of night expressions during the first week, MOM volume from day 3 till 2 weeks postnatally were enablers for MOM feeding (Table IV and Table V). Neither mode of expression (electronic versus manual) nor infant's stay in the hospital was a factor for any of the groups. 
Table IV. Comparison of baseline variables: MOM (Hospital Stay) group vs. formula or donor milk group.

\begin{tabular}{llll}
\hline Baseline variable & $\begin{array}{l}\text { MOM success } \\
(\mathrm{n}=43)\end{array}$ & $\begin{array}{l}\text { MOM failure } \\
(\mathrm{n}=44)\end{array}$ & P value \\
\hline Primigravida mother & $22(50 \%)$ & $23(53.5 \%)$ & 0.59 \\
Cesarean section & $34(77.7 \%)$ & $37(86 \%)$ & 0.74 \\
Maternal age (years) & $29(\mathrm{SD} \pm 4.3)$ & $29.5(\mathrm{SD} \pm 5.1)$ & 0.64 \\
Maternal PIH & $22(50 \%)$ & $23(53.5 \%)$ & 0.83 \\
Maternal diabetes & $9(20.5 \%)$ & $5(11.6 \%)$ & 0.38 \\
Education & & & \\
Matriculation & $18(40.9 \%)$ & $25(58.1 \%)$ & 0.10 \\
Intermediate & $14(31.8 \%)$ & $10(23.3 \%)$ & 0.30 \\
Graduate & $2(4.5 \%)$ & $2(4.7 \%)$ & 0.98 \\
Post graduate & $10(22.7 \%)$ & $6(14 \%)$ & 0.38 \\
Residence & & 0 & 0.045 \\
Rural & $5(11.4 \%)$ & $10(23.3 \%)$ & 0.29 \\
Semi urban & $6(13.6 \%)$ & $33(76.7 \%)$ & 0.84 \\
Urban & $33(75 \%)$ & $30.8(\mathrm{SD} \pm 2.2)$ & 0.64 \\
Gestation (week) & $30.6(\mathrm{SD} \pm 1.6)$ & $1179(\mathrm{SD} \pm 208)$ & 0.57 \\
Birth weight (gram) & $1213(\mathrm{SD} \pm 182)$ & $30(55 \%)$ & 0.19 \\
Male sex & $22(69 \%)$ & $9(20.9 \%)$ & 0.82 \\
ELBW & $7(15.9 \%)$ & $17(39.5 \%)$ & 0.59 \\
IUGR & $13(29.5 \%)$ & $8(\mathrm{IQR} 8-8)$ & 1.00 \\
APGAR 5min & $8(\mathrm{IQR} 8-8)$ & $36(83.7 \%)$ & 0.97 \\
RDS & $41(93.1 \%)$ & $19(44.18 \%)$ & 0.19 \\
HSPDA & $17(41.46 \%)$ & $6(13.9 \%)$ & 1.00 \\
Ventilation & $1(2.2 \%)$ & $30(69.76 \%)$ & 0.08 \\
HFNC/CPAP & $27(61.36 \%)$ & & \\
\hline
\end{tabular}

MOM: mother own milk, PIH: pregnancy induced hypertension, ELBW: extremely low birth weight (birth weight <1000 grams), IUGR: intra-uterine growth restriction, RDS: respiratory distress syndrome, HSPDA: hemodynamically significant patent ductus arteriosus CPAP: continuous positive pressure support, HFNC: high flow nasal canula, IQR: interquartile range, SD: standard deviation

\section{Discussion}

Mothers of preterm infants must express their breast milk by hand or use a pump and then the milk is given to the infant by an orogastric tube or gavage as per appropriate feeding mode for the infant in the initial phase after birth, with the aim of transitioning to direct breastfeeding. While some mothers find this transition to be easy some struggle. If the direct breastfeeding attempt is successful then this can be a sense of security and pride for mothers and if not, then they may experience shame, insufficiency, frustration, rejection, and setback which then may affect mother-infant bonding. ${ }^{6}$
Preterm infant's mother's journey from starting milk expression to attaining a full volume of milk can be challenging, among which stress and deficient lactation support are primary causative factors. Other factors may also delay lactogenesis stage two, leading to a less number of milk expressions and less breast milk volume. ${ }^{7}$ Other barriers for human milk feeding are the ambiguity of the premature condition of the infant, physical partition from the mother, suspicion of discharge, and maternal anxiety. ${ }^{8}$ Hobbs et al. ${ }^{9}$ observed that mothers who had received a C-section experienced more breastfeeding obstacles and lesser breastfeeding duration when compared to the 
Table V. Comparison MOM (Hospital Stay) group vs. formula or donor milk group.

\begin{tabular}{|c|c|c|c|}
\hline Factors & $\begin{array}{l}\text { MOM success } \\
(\mathrm{n}=43)\end{array}$ & $\begin{array}{l}\text { MOM failure } \\
(\mathrm{n}=44)\end{array}$ & P value \\
\hline Antenatal counseling & 0 & 0 & 0 \\
\hline Breastfeeding awareness & $5(12 \%)$ & $11(25 \%)$ & 0.18 \\
\hline Day 1 counseling & 0 & 0 & 0 \\
\hline $\begin{array}{l}\text { Proportion of the mothers who Expressed the milk on } \\
\text { Day1 after birth }\end{array}$ & $32(74 \%)$ & $32(73 \%)$ & 0.94 \\
\hline Time of first expression after birth (hours) & 16 (IQR 8-24) & 18 (IQR 13-26) & 0.23 \\
\hline Median number of expressions Day 1 after birth & 2 (IQR 0-2) & 1 (IQR 0-1) & 0.006 \\
\hline Median number of expressions in first 3 days after birth & 6 (IQR 5-7) & 5 (IQR 4-6) & 0.16 \\
\hline Median number of expressions in first week after birth & 17 (IQR 15-20) & 14 (IQR 12-18) & 0.24 \\
\hline Median number of night expressions in first week & 4 (IQR 4-5) & 3 (IQR 2-4) & 0.002 \\
\hline Median number of total Expressions in NICU stay & 78 (IQR 59-102) & 50 (IQR 23-108) & 0.069 \\
\hline \multicolumn{4}{|l|}{ Mode of expressions } \\
\hline Only pump & $30(70 \%)$ & $26(59 \%)$ & 0.29 \\
\hline Both (manual and pump) & $13(30 \%)$ & $18(41 \%)$ & \\
\hline Mother having Any Visit on Day 1 & $9(28 \%)$ & $3(5.5 \%)$ & 0.11 \\
\hline Maternal visit on day 1 (median numbers) & 0 (IQR 0-0) & 0 (IQR 0-0) & 0.11 \\
\hline Maternal visit on day 2-3 (median numbers) & 2 (IQR 1-3.5) & 1 (IQR 0-3) & 0.33 \\
\hline Maternal visit on day 4-7(median numbers) & 4 (IQR 3-7) & 4 (IQR 2-6) & 0.23 \\
\hline Maternal visits in the first week (median numbers) & 8 (IQR 5-9.5) & 6 (IQR 3-7) & 0.24 \\
\hline Minutes of visit on day 1 (median) & 0 (IOR 0-2.5) & 0 (IQR 0-1) & 0.11 \\
\hline Minutes of visit on day 2- 3 (median) & 16 (IQR 7-34) & 3 (IQR 0-18) & 0.24 \\
\hline Minutes of visit on day 4- 7(median) & 200 (IQR 48-521) & 76 (IQR 12-227) & 0.90 \\
\hline Time of first contact (in hrs) after birth with infant & 30 (IQR 25-49) & 40 (IQR 30-75) & 0.74 \\
\hline $\begin{array}{l}\text { Time of first Non-Nutritive sucking done for infant (day } \\
\text { of life after birth) }\end{array}$ & 8 (IQR 6-9.5) & 7.5 (IQR 6-11) & 0.69 \\
\hline $\begin{array}{l}\text { Non -Nutritive sucking (in Min) done for infant in the } \\
\text { first week }\end{array}$ & 0 (IQR 0-10) & 0 (IQR 0-5) & 0.59 \\
\hline Day of initiation of Skin to skin care for infant after birth & 8 (IOR 6-10) & 7.5 (IQR 6-11) & 0.88 \\
\hline Median duration of Skin to skin (hrs) done in NICU stay & 22 (IQR 11-42) & 18 (IQR 4-35) & 0.91 \\
\hline Median duration of KMC in first week & 0 (IQR 0-3) & 0 (IQR 0-2) & 0.90 \\
\hline Median MOM volume on day 1 & 1 (IQR 0-3) & 0 (IQR 0-1) & 0.064 \\
\hline Median MOM volume on day 2-3 & 16 (IQR 7-34) & 3 (IQR 0-18) & 0.02 \\
\hline Median MOM volume on day 4-7 & 200 (IQR 48-521) & 76 (IQR 12-227) & 0.024 \\
\hline Median MOM volume in 2nd week & 1177 (IQR 660-1535) & 110 (IQR 0-410) & $<0.000$ \\
\hline
\end{tabular}

MOM: mother own milk, NICU: neonatal intensive care unit, KMC: kangaroo mother care, IQR: interquartile range

mothers who had delivered vaginally. Evan et al. ${ }^{10}$ also showed that breastfeeding among the mothers who had received C-sections was significantly lesser in the first five days after the delivery when compared to mothers that had delivered vaginally. Similarly, Giannì et. al. ${ }^{5}$ and Scott et al. ${ }^{11}$ found that mothers who had received C-sections had significantly delayed lactation when compared to those who delivered vaginally. The mothers of preterm infants due to their early delivery had lowered milk production as there is deficient mammary gland development. ${ }^{12}$ Also, maybe due to the delayed lactogenesis two (initiation of full milk 
generation following the evacuation of the placenta after delivery), following the cesarean section which may cause a significant or lengthy maternal stress response and due to medical complications, which is especially common among the VLBW mothers., ${ }^{9,13}$ We did not find that a C-section was a barrier to successful MOM use, contrary to the findings of many studies. C-section rates were very high in our unit and similar between the 2 groups $(>70 \%)$.

Infant factors like EUGR and IUGR were shown to be significant barriers for MOM in the predischarge 48-hour group. To date, there are no studies concentrating on small for gestation age (SGA) newborns and the best mode of feeding. The limited data concerning premature infants less than 1500 grams shows that they are not capable of coordinated sucking, swallowing, and breathing, with little recognition of infants. ${ }^{11,14}$ Our findings are coherent with the findings of Meier et al. ${ }^{15}$ and Radtke et al. ${ }^{16}$, which mentions factors related to the infants, such as the fact that the varying degree of infant developmental immaturity can complicate the feeding situation. Preterm infants present with latching difficulty, lethargy, limited sucking, and metabolic disturbances that could further incline them to poor breastfeeding outcomes. Similarly, Jones et al. $^{17}$ assessed preterm breastfeeding practices and suggested that difficulties with proper latching, positioning, and coordination are commonly experienced.

Sisk et al. ${ }^{18}$ and Hurst et al. ${ }^{19}$ recognized that lack of motivation and support impairs the ability to frequently express breast milk. The unavailability of lactation professionals in the NICU and scarce supply of hospital grade pumps can also lead to less human milk utilization in VLBW infants. Flacking et al. ${ }^{20}$ and Swanson et al. ${ }^{21}$ showed that the expression of milk required resilience, motivation, and persistence. The education of staff and family regarding the priority of human milk for preterm infants, helping mothers express their own milk either manually or pumping, and assessing the latch of the newborn has been demonstrated to improve milk generation in the mothers of VLBW..$^{22,23}$

Giannì et al. ${ }^{5}$ suggested positive impact factors such as receiving support from a consultant or health care professional, prenatal counseling, mother and baby rooming for a prolonged time, early expression of breast milk, and expressing milk at a frequency of at least 6.25 times per day. The participant mothers in both groups from our study had not obtained structured counseling neither during the antenatal period nor the postnatal period by health care professionals specializing in breastfeeding practices, however in our study milk expression on the first day until the third day and night expressions in the first week postnatally were significantly higher in infants with MOM success group (pre discharge). The maternal role in terms of a visit on the first day after delivery to her infant as well as provision of MOM on the first day were also the predictors of successful MOM use in the hospital pre-discharge (48 hours prior) MOM group.

Early commencement of manual hand expression of breast milk resulted in a greater generation of human milk. ${ }^{23}$ Parker et al. ${ }^{24}$ detected a greater milk volume of human milk in mothers who initiated expression of milk in less than 1 hour after birth compared to those who expressed between one to six hours. In our study the first expression after the birth was more than 12 hours in both groups. Furthermore, repeated frequent expression of milk by the pump or by manual hand expression ended in a higher volume of human milk over time. ${ }^{25}$ The mode of expression of milk did not affect the MOM use in our study.

Flacking et al. ${ }^{20}$ indicated that maternal separation from their infants caused a loss of natural connection between the mother-infant dyad and the tie-in that starts when a term infant is breastfed right after birth was not experienced by the preterm infants and mothers after discharge. In our study, we noticed that a maternal visit on the first day and the number 
of maternal visits on the first day to NICU has a decisive impact on MOM use in preterm infants. Similarly, Ikonen et al. ${ }^{25}$ found that mothers who were separated from their infants had struggles in expressing their milk and breastfeeding, as well as feeling detachment.

The main limitations of our study was that it was a single-center study and most of the mothers were from high educational environments and that data on the psychological and emotional aspects of mothers were not incorporated in the study; hence the results may not relate to dissimilar settings.

In our study close to $50 \%$ of the mothers were predominantly feeding their infants with MOM during the entire hospital stay and nearly one third successfully preserved a full human milk supply to their infants at the time of hospital discharge. The ELBW infants and IUGR infants are at a greater risk of poor MOM use. The numbers of milk expressions until the third day, maternal visit on the first day, and average milk volume in the first 2 weeks are the crucial enablers of MOM use.

\section{Acknowledgement}

We are grateful to Dr Evita Fernandez head of the institute and Dr Pramod Gaddam, Head of the Department of Neonatology for their constant support and encouragement.

\section{Author contribution}

The authors confirm contribution to the paper as follows: study conception and design: DK, $\mathrm{SM}$; data collection: DP, VN, DS, VV, TB, DK, $\mathrm{SJ}, \mathrm{VK}$; analysis and interpretation of results: DK, VN, SK, DP, DS, VV, TB; draft manuscript preparation: SM, DK, SK. All authors reviewed the results and approved the final version of the manuscript.

\section{Ethical approval}

The study was approved by the ethical committee of the Fernandez Hospital (reference number 24-2017).

\section{Source of funding}

No funding involved.

\section{Conflict of interest}

None.

\section{REFERENCES}

1. Kumar RK, Singhal A, Vaidya U, Banerjee S, Anwar F, Rao S. Optimizing nutrition in preterm low birth weight infants-consensus summary. Front Nutr 2017; 4: 20.

2. DeMarchis A, Israel-Ballard K, Mansen KA, Engmann C. Establishing an integrated human milk banking approaches to strengthen newborn care. J Perinatol 2017; 37: 469-474.

3. Seah SY, Cheah FC. Empowering mothers of preterm infants for continuous breastfeeding in Malaysia. Perinatol 2017; 18: 81-89.

4. Morales Y, Schanler RJ. Human milk and clinical outcomes in VLBW infants: how compelling is the evidence of benefit? Semin Perinatol 2007; 31: 83-88.

5. Giannì ML, Bezze E, Sannino P, et al. Facilitators and barriers of breastfeeding late preterm infants according to mothers' experiences. BMC Pediatr 2016; $16: 179$.

6. Buckley KM, Charles GE. Benefits and challenges of transitioning preterm infants to at-breast feedings. Int Breastfeed J 2006; 1: 13.

7. Jones E, Spencer SA. Optimising the provision of human milk for preterm infants. Arch Dis Child Fetal Neonatal Ed 2007; 92: F236-F238.

8. Raines DA. Mothers' stressor as the day of discharge from the NICU approaches. Adv Neonatal Care 2013; 13: 181-187.

9. Hobbs AJ, Mannion CA, McDonald SW, Brockway $\mathrm{M}$, Tough SC. The impact of caesarean section on breastfeeding initiation, duration, and difficulties in the first four months postpartum. BMC Pregnancy Childbirth 2016; 16: 90. 
10. Evans KC, Evans RG, Royal R, Esterman AJ, James SL. Effect of caesarean section on breast milk transfer to the normal term newborn over the first week of life. Arch Dis Child Fetal Neonatal Ed 2003; 88: F380-F382.

11. Scott JA, Binns CW, Oddy WH. Predictors of delayed onset of lactation. Matern Child Nutr 2007; 3: 186-193.

12. Henderson JJ, Hartmann PE, Newnham JP, Simmer $\mathrm{K}$. Effect of preterm birth and antenatal corticosteroid treatment on lactogenesis II in women. Pediatrics 2008; 121: e92-e100.

13. Chapman DJ, Pérez-Escamilla R. Identification of risk factors for delayed onset of lactation. J Am Diet Assoc 1999; 99: 450-454.

14. Barone G, Maggio L, Saracino A, Perri A, Romagnoli C, Zecca E. How to feed small for gestational age newborns. Ital J Pediatr 2013; 39: 28.

15. Meier P, Patel AL, Wright K, Engstrom JL. Management of breastfeeding during and after the maternity hospitalization for late preterm infants. Clin Perinatol 2013; 40: 689-705.

16. Radtke JV. The paradox of breastfeeding-associated morbidity among late preterm infants. J Obstet Gynecol Neonatal Nurs 2011; 40: 9-24.

17. Jones E, Emmett C, Spencer SA. An evaluation of preterm breastfeeding information and support. Infant 2009; 5: 116-120.

18. Sisk P, Quandt S, Parson N, Tucker J. Breast milk expression and maintenance in mothers of very low birth weight infants: supports and barriers. J Hum Lact 2010; 26: 368-375.
19. Hurst N, Engebretson J, Mahoney JS. Providing mother's own milk in the context of the NICU: a paradoxical experience. J Hum Lact 2013; 29: 366373.

20. Flacking R, Ewald U, Nyqvist KH, Starrin B. Trustful bonds: a key to "becoming a mother" and to reciprocal breastfeeding. Stories of mothers of very preterm infants at a neonatal unit. Soc Sci Med 2006; 62: 70-80.

21. Swanson V, Nicol H, McInnes R, Cheyne H, Mactier $\mathrm{H}$, Callander E. Developing maternal self-efficacy for feeding preterm babies in the neonatal unit. Qual Health Res 2012; 22: 1369-1382.

22. Nyqvist $\mathrm{KH}$, Häggkvist $\mathrm{AP}$, Hansen $\mathrm{MN}$, et al; Baby-Friendly Hospital Initiative Expert Group. Expansion of the baby-friendly hospital initiative ten steps to successful breastfeeding into neonatal intensive care: expert group recommendations. J Hum Lact 2013; 29: 300-309.

23. Meier PP, Engstrom JL, Patel AL, Jegier BJ, Bruns NE. Improving the use of human milk during and after the NICU stay. Clin Perinatol 2010; 37: 217-245.

24. Parker LA, Sullivan S, Krueger C, Kelechi T, Mueller $\mathrm{M}$. Strategies to increase milk volume in mothers of VLBW infants. MCN Am J Matern Child Nurs 2013; 38: 385-390.

25. Ikonen R, Paavilainen E, Kaunonen M. Preterm infants' mothers' experiences with milk expression and breastfeeding: an integrative review. Adv Neonatal Care 2015; 15: 394-406. 